\title{
Энантиоселективность новых хиральных неподвижных фраз на основе пиридиниевых и имдазолевых ионных жидкостей
}

\author{
Шашков М.В. ${ }^{1,2}$, Сидельников В.Н. ${ }^{1,2}$ \\ ${ }^{1}$ Федеральное Государственное Бюджетное учреждение науки Институт катализа \\ им. Г.К. Борескова Сибирского отделения Российской академии наук, Новосибирск \\ ${ }^{2}$ Новосибирский государственный университет, факультет естественных наук, Новосибирск
}

Поступила в редакцию 31.01.2017 г.

В настоящее время основная часть ГХ-анализа энантиомеров производится на колонках с неподвижными жидкими фазами (НЖФ) на основе циклодекстринов. В работе изучена энантиоселективность ряда новых хиральных фаз на основе имидазолевых и пиридиниевых ионных жидкостей (ИЖ). Рассмотрены два подхода к созданию хиральных НЖФ на основе ИЖ. Первый предполагает использование смеси нехиральной ИЖ в качестве матрицы и хиральной добавки, которой является модифицированный циклодекстрин. Другой подход предполагает использование хиральной ИЖ в качестве индивидуальной НЖФ. В работе рассмотрены возможные пути приготовления колонок на основе энантиоселективных НЖФ с использованием пиридиниевых и имидазолиевых ионных жидкостей. Впервые использованы ИЖ с хиральным анионом и показано, что использование данного варианта хиральной НЖФ позволяет получать коэффициенты энантиоселективности того же порядка что и для циклодекстриновых НЖФ.

Ключевые слова: газовая хроматография, ионные жидкости, разделение энантиомеров.

\section{Enantioselectivity of new chiral stationary phases based on pyridinium and imidazolium ionic liquids}

\author{
Shashkov M.V. ${ }^{1,2}$, SidelnikovV.N. ${ }^{1,2}$ \\ ${ }^{I}$ Boreskov Institute of Catalysis SB RAS, Novosibirsk \\ Novosibirsk State University, Novosibirsk
}

\begin{abstract}
The search for new systems for the analysis of chiral compounds is of interest in connection with the development of methods for stereoselective organic synthesis and increase requirements for optical purity of pharmaceuticals. For the analysis of volatile chiral compounds (or substances, which can be converted to gaseous state) the most effective method is gas chromatography (GC) on columns with chiral stationary liquid phases (SLP). Currently the main part of the GC analysis of enantiomers is performed on columns with SLP based on cyclodextrins. The aim of the work is obtaining and studying the selectivity of a number of new chiral phases based on imidazolium and pyridinium ionic liquids (ILs). Two possible ways of making chiral columns based on pyridinium and imidazolium ionic liquids were investigated. The first involves the use of a mixture of non-chiral IL as a matrix, and a chiral additive, which is a modified cyclodextrin. Another approach involves the use of a chiral IL with chiral anon (L-tartrate and L-alanine) as the individual SLP.

In the paper studied possible ways of making columns with enantioselective SLP using pyridinium and imidazolium ionic liquids. First used ILs with chiral anion and it is shown that the use of this kind of chiral IL allows one to obtain the coefficients of enantioselectivity the same order as for ciclodextrin SLP. Currently, no established methods of obtaining high-efficiency columns based on the IL. However, in the development of successful methods of coating capillary columns with a SLP based on ILs can be a new sepa-
\end{abstract}


ration instrument which can be solve the analytical problems, which to date has not been resolved since their properties are different from the cyclodextrin columns.

Keywords: gas chromatography, ionic liquids, enantiomer separation.

\section{Введение}

Химические процессы с участием оптически-активных веществ является динамично развивающейся областью современной химии. Исследования в этой области имеют важное значение для развития фундаментальных и прикладных аспектов современной биологии, медицины, фармакологии и смежных областей [1]. Для анализа летучих хиральных соединений (либо веществ, которые можно перевести в летучее состояние) наиболее эффективным является метод газовой хроматографии (ГХ) на колонках с хиральными неподвижными жидкими фазами (НЖФ). В настоящее время ГХ анализ энантиомеров производится лишь на двух типах колонок - колонка с НЖФ на основе циклодекстринов (ЦД-фазах) и на так называемых «валиновых фазах» [2]. Однако данные фазы имеют ряд ограничений и не охватывают постоянно расширяющийся спектр задач хирального анализа. Недостатком ЦД-фаз является их невысокая максимальная температура $\left(240^{\circ} \mathrm{C}\right)$, чувствительность к следам окислителей (в аналитах или газе-носителе), что приводит к значительному уменьшению времени их жизни. Термостабильность валиновых фаз еще ниже $\left(200^{\circ} \mathrm{C}\right)$, и они имеют узкую сферу применения - анализ аминокислот и аминов [3]. Другим недостатком существующих хиральных фаз является то, что в качестве матрицы для циклодекстрина используют слабополярные полисилоксаны. Как правило в хиральном анализе приходится иметь дело с полярными аналитами (кислород-, серо- и азот-содержащие). Поэтому, было бы уместно использование полярной матрицы, что позволяет улучшить эффективность и форму пика для полярных аналитов и улучшить разделение между парами энантиомеров в сложных объектах. Кроме того, использование полярной фазы, положительно сказывается и на энантиоселективности, так как в этом случае сильнее проявляются специфические взаимодействия, которые оказывают решающее значение на взаимодействие энантиомеров с хиральными фрагментами НЖФ [4].

Поэтому необходим поиск новых классов неподвижных фаз, которые были бы лишены указанных выше недостатков. С этой точки зрения представляется интересным использование хиральных НЖФ на основе ионных жидкостей (ИЖ). ИЖ являются новым классом НЖФ, которые обладают рядом значительных преимуществ по сравнению с традиционными фазами. Они являются как высокополярными, так и термостабильными (до $300^{\circ} \mathrm{C}$ ) [5], и в то же время устойчивыми к окислению [6]. Кроме того, структурное ядро катиона ИЖ позволяет проводить его химические модификации, что дает возможность создать большой набор структур, обладающих различными свойствами. Это открывает новые возможности для дизайна новых классов хиральных НЖФ.

В настоящее время опубликовано немного работ где ИЖ успешно использованы в качестве фаз для разделений энантиомеров [7]. Это связано с тем, что эффективность для колонок с ИЖ ниже по сравнению с традиционными фазами [8]. Поэтому даже при достаточной селективности фазы, разделить пару энантиомеров затруднительно.

Существует два подхода к созданию хиральных НЖФ на основе ИЖ. Первый предполагает использование смеси нехиральной ИЖ в качестве матрицы НЖФ и хиральной добавки, которой обычно является модифицированный циклодекстрин (ЦД) [9]. Другой подход предполагает использование хиральной ИЖ в качестве индиви-

Шашков и др. / Сорбционные и хроматографические процессы. 2017. Т. 17. № 2 
дуальной НЖФ. В научной периодике можно найти работы посвященные изучению селективности ИЖ на основе хирального имидазольного или амонийного катиона [811]. Однако вопрос об использовании НЖФ с ИЖ на основе хирального аниона в настоящее время не ставился.

В данной работе приведены результаты по исследованию хиральных фаз для ГХ, где в качестве матрицы использованы новые пиридиновые и имидазолевые ИЖ с гидрофобным анионом и обладающие высокой полярностью и термической стабильностью в смеси с ЦД, а также впервые изучена энантиоселективность НЖФ на основе ИЖ с анионами на основе L-винной кислоты и L-аланина.

\section{Эксперимент}

Материалы и реактивы. Реактивы для синтезов: литий бис(трифторметилсульфонил)имид ( $\left.\mathrm{LiNtf}_{2}\right)$ (99\%, Acros), $\beta$-циклодекстрин $(98 \%$, Sigma-Aldrich), per-Ме- $\beta$-циклодекстрин (98\%, Sigma-Aldrich), остальные производства ALFA AESAR: 1-бромбутан (99\%), 1-бромгексан (99\%), 1-бромдекан (99\%), 1,9дибромнонан (99\%), 2-метилпиридин $\quad$ (99\%), 4-метилпиридин $\quad(99 \%), \quad 3,5-$ диметилпиридин (99\%), ангидрид трифторуксусной кислоты (98\%), триэтиламин (96\%), диметиламинопиридин (98\%).

Растворители для синтезов и нанесения фаз квалификации ХЧ и ОСЧ: дихлорметан, этилацетат, ацетонитрил. Тестовые вещества и компоненты тестовых смесей производства ALFA AESAR.

Синтез ЦД. Для приготовления НЖФ были использованы следующие производные $\beta$-циклодекстрина: гептакис $(2,3,6$-три-О-метил)- $\beta$-циклодекстрин (per-Me- $\beta$ CD) и гептакис (2,6-ди-О-гексил-3-О-трифторметил)- $\beta$-циклодекстрин (2.6-Hex-3Tfa- $\beta$-CD). Per-Me- $\beta$-CD был приобретён в готовом виде у Sigma-Aldrich. 2.6-Hex-3Tfa- $\beta$-CD был синтезирован. Синтез проводили по методике указанной в [4]. В качестве исходного вещества был взят $\beta$-циклодекстрин, затем последовательно проводилось алкилирование бромгексаном и ацилирование с помощью трифторуксусного ангидрида. Полученный после очистки продукт был использован для приготовления НЖФ.

Синтез ИЖ. Структуры синтезированных ИЖ приведены на рис. 1. ИЖ $\mathrm{C}_{8} \mathrm{MImAla}$ (6) была любезно предоставлена проф. Карцовой Л.А. (каф. орг. химии хим. фак. СПбГУ). Синтез ИЖ bis4МРу (3) и bis2MРу (2) был проведен нами ранее и описан в [12]. Синтез $\mathrm{C}_{10} \mathrm{MIm}$ (1) был проведен по методикам аналогичным для других имидазолевых ИЖ, синтезированных нами ранее [12].

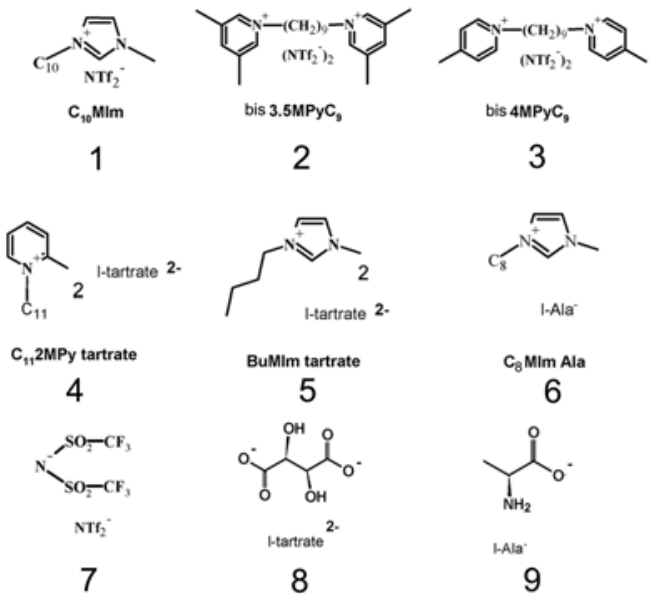

Рис. 1. Используемые в работе ИЖ (1-6) и структуры их анионов (7-9) 
Для синтеза ИЖ с тартрат анионом: BuMIm tatrtrate (5) и $\mathrm{C}_{11} 2 \mathrm{MPy}$ tartrate (4) на первой стадии синтезировались соответствующие бромиды по методикам описанным нами в ранних работах $[5,12]$. Затем, на второй стадии проводили обмен аниона с использованием ионообменной смолы Amberlite IRA400 (OH) (Supelco) как описано в [13].

Приготовление капиллярных колонок. Для приготовления колонок использовался кварцевый капилляр (Polymicro) с внутренним диаметром 0.25 мм. Для приготовления колонок был использован статический метод низкого давления согласно методики, описанной в [8], растворитель для нанесения - дихлорметан с добавкой ацетона. Ацетон добавляли в количестве минимально необходимом для растворения ИЖ $(0.5-1 \%(\mathrm{v} / \mathrm{v}))$. В результате были получены колонки с расчетной толщиной пленки 0.2 мкм и длиной 20 м. Эффективность полученных колонок была равна порядка 1500-2000 теор. тарелок/м (измерение по пику 2,6-диметилфенола при $120^{\circ} \mathrm{C}$ ).

Проведение измерений. Для испытаний колонок и измерений энантиоселективности характеристик использовали хроматограф Agilent 7890 с автосамплером. Во всех измерениях температура инжектора составляла $250^{\circ} \mathrm{C}$, и гелий был использован в качестве газа-носителя. Температура колонок для каждого измерения приведена в табл. 1.

Таблица 1. Энантиоселективность изучаемых в работе НЖФ относительно хиральных изомеров 1-фенилэтанола, миртеналя и карвона

\begin{tabular}{|c|c|c|c|c|c|c|c|c|c|}
\hline & \multicolumn{3}{|c|}{ (R/S)-1-фенилэтанол } & \multicolumn{3}{|c|}{ (+/-)-миртеналь } & \multicolumn{3}{|c|}{ (+/-)-карвон } \\
\hline & $k$ & $\mathrm{~T}^{\circ} \mathrm{C}$ & $\alpha$ & $k$ & $\mathrm{~T}^{\circ} \mathrm{C}$ & $\alpha$ & $k$ & $\mathrm{~T}^{\circ} \mathrm{C}$ & $\alpha$ \\
\hline $\begin{array}{c}\mathrm{C}_{10} \mathrm{MIm} \\
(20 \% \text { per-Me- } \beta \text {-CD })\end{array}$ & 11.9 & 130 & 1.003 & - & - & - & - & - & - \\
\hline $\begin{array}{c}\text { bis } 35 \mathrm{MPyC}_{9} \\
(33 \% \text { per-Me- } \beta-\mathrm{CD})\end{array}$ & 4.17 & 120 & 1.008 & - & - & - & - & - & - \\
\hline $\begin{array}{c}\text { bis } 4 \mathrm{MPyC}_{9} \\
(20 \% \text { per-Me- } \beta-\mathrm{CD})\end{array}$ & 10.7 & 110 & 1.006 & 7.1 & 100 & 1.006 & 8.8 & 110 & 1.004 \\
\hline $\begin{array}{c}\text { bis } 4 \mathrm{MPyC}_{9} \\
(20 \% 2.6-2.6-\mathrm{Hex}-3-\mathrm{Tfa}-\beta-\mathrm{CD})\end{array}$ & 12.1 & 110 & 1.01 & 11.2 & 100 & 1.015 & 15.6 & 110 & 1.011 \\
\hline BuMIm tartrate & 13 & 150 & 1.004 & 4.6 & 100 & 1.007 & 4.78 & 110 & 1.016 \\
\hline $\mathrm{C}_{11} 2 \mathrm{MPy}$ tartrate & 7.5 & 130 & 1.004 & 7.95 & 90 & 1.003 & 6.56 & 100 & 1.008 \\
\hline
\end{tabular}

Ввиду недостаточной эффективности колонок, определение селективности проводили путем последовательного ввода хиральных изомеров. Такого рода измерения возможны так как Agilent 7890, который позволяет при использовании автосамплера воспроизводить времена удерживания с точностью до 0.00001 сек [14]. При использовании данного подхода проводили измерения при постоянной температуре одного из хиральных изомеров, измеряли время удерживания по времени элюирования верхушки пика. Затем вводили другой изомер и тоже проводили измерение времени удерживания, данную процедуру повторяли 3 раза. Из усредненных данных по временам удерживания вычисляли коэффициент селективности $\alpha$. Разница во временах выхода в большинстве измерений составляла 2-60 сек. В тех случаях, когда разница времен удерживания изомеров при двух последовательных вводах составляла менее 2 секунд, считалось, что энантиомеры не делятся. 


\section{Обсуждение результатов}

Хиральные фазы с циклодекстрином. Измерения энантиоселективности проводили по трем молекулам: миртеналь, карвон и 1-фенилэтанол. Результаты измерений энантиоселективности представлены в таблице 1. Для каждого вещества приведена температура, при которой на данной НЖФ достигнуто наибольшее значение коэффициента селективности $\alpha$. Так же приведено значение фактора удерживания $(k)$ которое относится к первому из изомеров пары, элюируемых при данной температуре. Наконец, для каждого вещества приведено значение коэффициента селективности $\alpha$, которых характеризует разделение энантиомеров.

На первом этапе были исследованы колонки с фазами на основе перметилированного $\beta$-циклодекстрина (per-Me- $\beta$-CD) в матрице имидазолевой $\left(\mathrm{C}_{10} \mathrm{MIm}(20 \%\right.$ per-Me- $\beta-\mathrm{CD}$ ) и дикатионных пиридиниевых ИЖ (bis4MРуС ${ }_{9}$ и bis $35 \mathrm{MPyC}_{9}$ ).

В случае НЖФ bis $35 \mathrm{MPyC}_{9}$ (33\% per-Me- $\left.\beta-\mathrm{CD}\right)$ и bis4МРуС 9 (20\% per-Me- $\beta$ $\mathrm{CD})$ селективность для миртеналя и карвона оказалась мала и измерить её значение не удалось. В случае НЖФ bis $4 \mathrm{MPyC}_{9}(20 \%$ per-Me- $\beta-\mathrm{CD})$ для всех исследованных веществ получено разделение хиральных изомеров. Тем не менее, во всех случаях с per-Me- $\beta$-CD энантиоселективность $\alpha$ оказалась менее чем 1.01. Здесь следует отметить, что при использовании НЖФ на основе циклодекстринов невозможно предсказать, будет ли происходить разделение энантиомеров на той или иной фазе [15]. Однако известно, что ЦД с трифторацетильными - алкильными заместителями $[4,15]$ показывают более высокую селективность по большинству аналитов в сравнении с перметилированным ЦД. Поэтому, чтобы достичь более высокой энантоселективности, мы использовали гексил-трифторацетил-циклодекстрин. Рассмотрим как меняется селективность при использовании НЖФ содержащей гексил-трифторацетилциклодекстрин (2.6-Hex-3-Tfa- $\beta$-CD) при разделении энантиомеров. Данный циклодектрин использован для приготовления фазы, где в качестве матрицы была выбрана ИЖ bis4MРуС 9 (см. рис.1). Видно (табл.1), что наблюдается энантиоселективность заметно выше, чем для НЖФ с per-Me- $\beta$-CD. Для энантиомеров 1-фенилэтанола, миртеналя и карвона коэффициент селективности $\alpha$ при использовании (2.6-Hex-3Tfa- $\beta$-CD) находится в области 1.01-1.015. Тем не менее, ввиду низкой эффективности колонок эта селективность оказывается недостаточной для разделения энантиомеров тестируемых веществ. Кроме того, наличие ЦД в НЖФ не решает проблемы недостаточной термической и окислительной стабильности описанных выше хиральных НЖФ. Поэтому встает задача поиска совершенно новых фаз для разделения энантиомеров. Интересным с этой точки зрения представляют использование ИЖ с хиральной структурой.

Ионные жидкости с хиральным анионом. Известны работы, где описано применение ИЖ с хиральным катионом в качестве НЖФ [8-11]. Хотя на основе данных НЖФ показана энантиоселективность хиральных ИЖ по ряду аналитов, практически не было получено хороших разделений ввиду низкой эффективности приготовленных колонок [8-11]. С другой стороны, не найдено работ, где бы НЖФ являлась ИЖ с хиральным анионом. Меж тем данный подход к созданию НЖФ интересен с той точки зрения, что, что существуют уже готовые хиральные анионы, например тартрат-анион (рис. 1.8) или анион на основе аминокислоты аланина (рис. 1.9), которые в паре с нехиральным катионом смогут образовать хиральную НЖФ.

Рассмотрим в качестве аниона тартрат (рис. 1.8). Данный анион обладает двумя близкорасположенными хиральными центрами, что должно сказаться на энантиоселективности. В работе синтезировано две ИЖ с L-тартрат анионом: BuMIm tartrate и $\mathrm{C}_{11} 2 \mathrm{MPy}$ tartrate (рис. 1). Измеренная энантиоселективность этих 
ИЖ отличается от той, что получена в случае с bis4MPyC 9 (20\% 2.6-Hex-3-Tfa- $\beta$-CD). Например, для BuMIm tartrate по карвону селективность оказалась выше, в то время как по миртеналю ниже. Это указывает на то, что механизмы взаимодействий приводящих к хиральному удерживанию аналитов отличаются для фаз на основе ИЖ с хиральным анионом и для циклодекстринов. Если сравнивать BuMIm tartrate и $\mathrm{C}_{11} 2 \mathrm{MPy}$ tartrate, то видно, что их селективность для карвона и миртеналя существенно отличается, для пиридиниевой ИЖ она меньше. Можно сделать вывод о том, что природа катиона вносит ощутимый вклад в механизм хирального удерживания энантиомеров.

Еще один анион, испытанный нами - это анион на основе простой аминокислоты L-аланина. В данной работе мы исследовали имидазолевую ИЖ - $\mathrm{C}_{8} \mathrm{MImAla}$ (рис.1). Испытание колонки, полученной на основе данной ИЖ не приведены в табл.1, поскольку данная ИЖ в качестве НЖФ непригодна для работы с активными кислородсодержащими соединениями такими как спирты, карбонильные соединения. Данные вещества из колонки не элюируются. Вероятно, это связано с высокой активностью свободной аминогруппы аминокислоты. Однако в то же время можно полагать, что данная колонка будет пригодна для анализа основных соединений. И действительно, при использовании данной колонки удалось получить элюирование аминов. Пример элюирования хиральных аминов на колонке с НЖФ $\mathrm{C}_{8} \mathrm{MImAla}$ приведен на рис. 2. Данный рисунок представляет собой наложение двух последовательно полученных в одних и тех же условиях хроматограмм. В качестве энантиомеров хиральных аминов была использована пара R,R-циклогексилдиамина и S,Sциклогексилдиамина. Для указанной пары энантиомеров нам был измерен коэффициент селективности, который составил 1.006 . И хотя разделения получить не удалось ввиду недостаточной эффективности колонки, при наложении хроматограмм соответствующих отдельному энантиомеру (рис. 2) можно наблюдать, что пики имеют заметное (более 30 сек.) отличие во временах удерживания. Поэтому данные вещества вполне могут быть разделены, если будут предприняты меры по увеличению эффективности колонки. в том случае, когда будет создана методика нанесения пленки данной фазы приводящей к получению эффективных колонок.

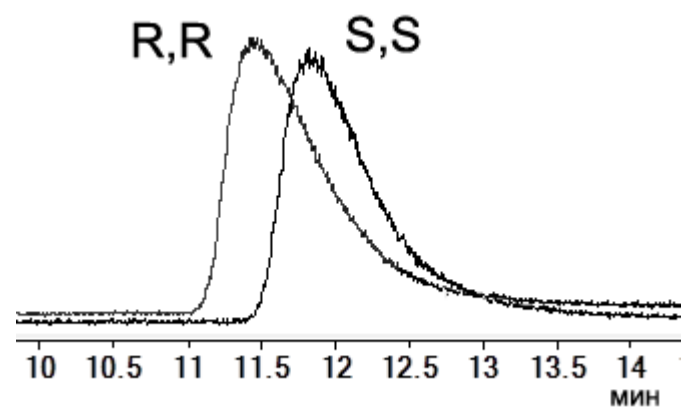

Рис. 2. Наложение хроматограмм энантиомеров циклогексилдиамина на колонке с $\mathrm{C}_{8}$ MImAla. Колонка 20м х 0.25 мм х 0.25 мкм.

Температура термостата: $140^{\circ} \mathrm{C}$, газ-носитель: гелий.

Если посмотреть на полученные значения коэффициента селективности $\alpha$, то можно задаться вопросом о том, действительно ли величины этих значений достаточно для того, чтобы получить разделения реальные разделения энантиомеров с использованием исследованных соединений в качестве НЖФ. Но если посмотреть на Вместе с тем, значения коэффициентов селективности для циклодекстриновых фаз, применяемых в настоящее время для разделения энантиомеров, то можно увидеть, что имеют типичные значения $\alpha$ для них, например при разделении изомеров карво- 
на, находятся в области 1.0065-1.015, что соответствует области полученных нами значений [15].

\section{Заключение}

Таким образом, рассмотрены возможные пути приготовления колонок на основе энантиоселективных НЖФ с использованием пиридиниевых и имидазолиевых ионных жидкостей. Впервые использованы ИЖ с хиральным анионом и показано, что использование данного варианта хиральной ИЖ позволяет получать коэффициенты энантиоселективности того же порядка что и для циклодекстриновых НЖФ. В настоящее время нет устоявшихся способов получения высокоэффективных колонок на основе ИЖ. Однако, при разработке удачных методик нанесения капиллярные колонки с НЖФ на основе ИЖ могут оказаться инструментом разделения, по своим свойствам отличающихся от колонок, полученных для ЦД и обеспечить решение аналитических задач, которые к настоящему времени не решены.

\section{Список литературы}

1. Scriba G.K.E. // J. Pharm. Biomed. Anal. 2002. Vol. 27. No 3-4, pp. 373-399.

2. Schurig V. // J. Chromatogr. A. 1994. Vol. 666, pp. 111-129.

3. HP-Chirasyl-Val, application note., Agilent tech. 2010.

4. Kenig W.A. Gas Chromatographic enantiomer separation with modified cyclodextrins. Heidelberg, Huthig, 1992, 132 p.

5. Shashkov M.V., Sidelnikov V.N. // Anal. Bioanal.Chem. 2012. Vol. 403. No 9, pp. 26732681.

6. Wasserscheid P., Welton T. Ionic liquids in synthesis. Weincheim, Germany, Wiley-VCH Verlag Gmbh\&Co. KGaA, 2002, 355 p.

7. Shamsi S. A., Danielson N.D. // J. Sep. Sci. 2007. Vol. 30. No 11. pp. 1729-1750.

\section{References}

1. Scriba G.K.E., J. Pharm. Biomed. Anal, 2002, Vol. 27, No 3-4, pp. 373-399. doi: 10.1016/S0731-7085(01)00653-7

2. Schurig V., J. Chromatogr. A, 1994, Vol. 666, pp. 111-129. Doi: 10.1016/00219673(94)80374-9

3. HP-Chirasyl-Val, application note., Agilent tech. 2010.

4. Kenig W.A. Gas Chromatographic enantiomer separation with modified cyclodextrins. Heidelberg, Huthig, 1992, 132 p.
8. Ding J., Welton T., Armstrong D.W. // Anal. Chem. 2004. Vol. 76, No 22. pp. 68196822.

9. Berthod A., He L., Armstrong D.W. // Chromatographia. 2001. Vol. 53. No 1-2. pp. 63-68.

10.Tran C. D., Oliveira D., Yu S.F. // Anal. Chem. 2006. Vol. 78. No 4. pp. 1349-1356.

11.Zhao L., Ai P., Duan AH. et al. // Anal. Bioanal. Chem. 2011. No 399. pp. 143-147.

12.Shashkov M.V., Sidelnikov V.N. // J. Chromatogr. A. 2013. No 1309. pp. 56-63.

13.Zhang Y., Tu T., Miao C., et al. // $A d-$ vanced. Materials. Research. 2012. Vol.. 518523. pp. 3989-3992.

14.Газовый хроматограф Agilent 7890B. Брошюра, Agilent Technologies, 2013.

15.Ткачев А.В. // Усnехи химии. 2007. Т. 76. № 10. C. 1014-1033.

5. Shashkov M.V., Sidelnikov V.N., Anal. Bioanal. Chem., 2012, Vol. 403, No 9, pp. 2673-2681. doi:10.1007/s00216-012-6020-9

6. Wasserscheid P., Welton, T. Ionic liquids in synthesis. Weincheim, Germany, Wiley-VCH Verlag Gmbh\&Co. KGaA, 2002, 355 p.

7. Shamsi S.A., Danielson N.D., J. Sep. Sci., 2007, Vol. 30, No 11, pp. 1729-1750. DOI: $10.1002 /$ jssc. 200700136

8. Ding J., Welton T., Armstrong D. W., Anal. Chem., 2004, Vol. 76, No 22, pp. 68196822. DOI: $10.1021 / \mathrm{ac} 049144 \mathrm{c}$ 
9. Berthod A., He L., Armstrong D. W., Chromatographia, 2001, Vol. 53, No 1-2, pp. 63-68. doi:10.1007/BF02492429

10.Tran C.D., Oliveira D., Yu S.F., Anal. Chem., 2006, Vol. 78, No 4, pp. 1349-1356. doi: 10.1016/j.ab.2006.06.026

11.Zhao L., Ai P., Duan AH. et al, Anal. Bioanal. Chem., 2011, No 399, pp. 143-147. doi:10.1007/s00216-010-4079-8

12.Shashkov M.V., Sidelnikov V.N., J. Chromatogr. A., 2013, No 1309, pp. 56-63. 10.1016/j.chroma.2013.08.030

Шашков Михаил Вадимович - научный сотрудник Институт Катализа СО РАН, кандидат химических наук. Новосибирск, тел. 8(383)3269644

Сидельников Владимир Николаевич - зав. Аналитической лаборатории Института Катализа СО РАН, доктор химических наук, профессор. Новосибирск, тел. 8(383)3269568
13.Zhang Y., Tu T., Miao C., et al, Advanced Materials Research, 2012, Vol. 518-523, pp. 3989-3992.

doi:10.4028/www.scientific.net/AMR.518-

523.3989

14. Gas chromatrograph Agilent 7890B, brochure, Agilent Technologies, 2013.

15.Tkachev A.V., Uspekhi khimii, 2007, Vol. 76, No10, pp. 1014-1033.

Shashkov Mikhail V. - Ph. D., researcher in Boreskov Institute of Catalysis SB RAS, Novosibirsk E-mail: shashkov@catalysis.ru, corresponding author

Sidelnikov Vladimir N. - Ph. D. Doctor science, head of analytical laboratory in Boreskov Institute of Catalysis SB RAS, Novosibirsk E-mail: vlad@,catalysis.ru 